\title{
Epidemiology of arterial hypertension in patients scheduled for elective hip replacement
}

\author{
Pawel Legosz', Filip M. Szymanski ${ }^{2}$, Anna Rys', Karolina Semczuk', Anna E. Platek², \\ Alicja Dudzik-Plocica', Dariusz Gorko', Marcin Kotkowski ${ }^{2}$, Krzysztof Ozieranski', \\ Agata Tyminska' ${ }^{2}$ Krzysztof J. Filipiak' ${ }^{2}$ Pawel Maldyk ${ }^{1}$
}

'Department of Orthopedics and Traumatology of the Musculoskeletal System, Medical University of Warsaw, Warsaw, Poland

${ }^{2} 1$ st Department of Cardiology, Medical University of Warsaw, Warsaw, Poland

\begin{abstract}
Background: Assessment of blood pressure values and early diagnosis of hypertension are especially important in high-risk group, including patients in preoperative and postoperative period. The aim of the current study was the assessment of blood pressure values and prevalence of hypertension in patients undergoing elective hip replacement surgery - an orthopedic procedure associated with one of the highest cardiovascular complication rate.

Material and methods: Two hundred and eighty-four consecutive patients admitted for elective hip replacement surgery were screened for arterial hypertension. All patients had their medical records reviewed for prior diagnosis and had their blood pressure measured on admission by a qualified physician prior to the procedure, according to the current guidelines. Results: The mean age of the study population was $62.2 \pm 13.9$ years and $42.7 \%$ of the patients were male. The body mass index (BMI) in the study population was $27.0 \pm 4.2 \mathrm{~kg} / \mathrm{m}^{2}$. Fifty-eight point two percent of patients were diagnosed with arterial hypertension previously. Mean blood pressure values on admission for systolic blood pressure (SBP) and diastolic blood pressure (DBP) were $134.5 \pm 20.4$ and $78.6 \pm 13.1 \mathrm{~mm} \mathrm{Hg}$, respectively. In $43.2 \%$ of patients, the on admission blood pressure values exceeded the threshold of $\geq 140$ and $/$ or $90 \mathrm{~mm} \mathrm{Hg}$. Arterial hypertension was diagnosed de novo in $33(15.0 \%)$ patients. Patients with the disease were older $(67.5 \pm 12.3$ vs. $54.4 \pm 13.9$ years; $\mathrm{p}<0.0001)$, and had higher BMI $\left(27.6 \pm 4.3\right.$ vs. $\left.26.2 \pm 3.8 \mathrm{~kg} / \mathrm{m}^{2} ; \mathrm{p}=0.05\right)$ than patients without the diagnosed disease. Diabetes mellitus was more often found in hypertensive patients ( $13.3 \%$ vs. $3.3 \% ; \mathrm{p}=0.02)$, they also more often had history of myocardial infarction $(\mathrm{p}=0.02)$, stable coronary artery disease $(\mathrm{p}=0.001)$ and heart failure $(\mathrm{p}=0.006)$ compared to patients without the diagnosis. Conclusions: The majority of patients scheduled for elective hip replacement surgery is diagnosed with arterial hypertension. The disease is also diagnosed de novo in $15 \%$ of these patients. Screening for arterial hypertension is important in this group of patients and can potentially reduce the complication rates of the hip replacement surgery. Key words: arterial hypertension, orthopedics, hip replacement
\end{abstract}

Arterial Hypertens. 2016, vol. 20, no. 1, pages: 11-15

DOI: $10.5603 / A H .2016 .0003$

\section{Background}

Arterial hypertension is one of the most prevalent chronic diseases [1]. The comparison of results of NATPOL 2011 and NATPOL demonstrate that in Poland the number of people suffering from arterial hypertension is $2 \%$ higher than a decade ago. Currently, approximately $32 \%$ of adult Poles (10.5

\footnotetext{
Address for correspondence: Filip M. Szymanski, MD, PhD 1A Banacha Street, 02-097 Warsaw, Poland e-mail: filip.szymanski@wum.edu.pl
}

M Copyright (C) 2016 Via Medica, ISSN 2449-6170 million patients, including 9.5 million aged 18-79 years and almost 1 million patients over 80 years) suffer from arterial hypertension. As many as 30\% of this population is not aware of the fact that they are afflicted with the disease and $9 \%$ have recognized, but untreated hypertension [2].

The results of large prospective epidemiological studies clearly indicate that hypertension is one of the most important risk factors for cardiovascular diseases such as coronary artery disease, heart failure, or stroke [3]. Moreover, arterial hypertension is responsible for considerable morbidity, mortality, and 
disability, not only in Poland but also across the Europe and the United States [4]. Even the "high-normal" blood pressure values, still within the normal range, have been linked with a higher incidence and severity of various cardiovascular disease risk factors such as obesity, dyslipidemia or glucose intolerance [5].

Assessment of blood pressure values and early diagnosis of hypertension is especially important in high-risk group, including patients in preoperative and postoperative period. Hypertension correlates with higher perioperative risk leading to severe and minor cardiovascular complications [6]. The aim of the current study was the assessment of blood pressure values and prevalence of hypertension in patients undergoing elective hip replacement surgery - an orthopedic procedure associated with one of the highest cardiovascular complication rate.

\section{Material and methods}

We performed an observational cohort study in order to establish the prevalence of arterial hypertension in consecutive Polish patients undergoing total hip replacement surgery in a tertiary University Hospital. The study was conducted with respect to the Declaration of Helsinki and an approval form the Ethics Committee by the Medical University of Warsaw was obtained before the beginning of the study. Written, informed consent was obtained from every study participant prior to the study enrolment.

The study cohort consisted of 284 consecutive patients who were hospitalized in a high-volume tertiary university orthopedic clinic for total hip replacement surgery between 2009 and 2013. All patients were qualified for the surgery procedure following current orthopedic criteria. The study population consisted of patients in whom the operation was successfully performed, and in whom the medical records allowed valid assessment of blood pressure values and current medical treatment.

Exclusion criteria were: age $<18$ or $\geq 75$ years, prior hip homolateral hip replacement surgery, stroke or decompensation of heart failure within the last six months and absence of written informed consent. Registry was screened to identify all patients who received one or more elective primary total hip or knee replacements in the study period. Patients treated with non-elective hip arthroplasty for hip fracture were excluded. For patients who underwent more than one operative procedure during the study period, only the first procedure was considered; thus, only one operative episode was examined for each patient.
Data on demographics, lifestyle, comorbidity and cardiovascular risk factors were obtained. Demographic variables analyzed included age and sex. Comorbidities studied included presence or absence of heart failure, diabetes mellitus, stroke or TIA episodes, myocardial infarction episodes, peripheral artery disease, dyslipidemia, coronary artery disease, important valvular defect, asthma, chronic obstructive pulmonary disease, CABG, PCI, cardiac pacemaker implanted. All patients were also screened for other classical and non-classical cardiovascular risk factors including diabetes mellitus, dyslipidemia, or history of cardiovascular disease. Diagnosis of all factors was made based on eligible medical records, taking prescription drugs applicable for the respective disease (i.e. hypoglycemic agents for diabetes), or as a de novo diagnosis according to the current diagnostic criteria.

All study participants were screened for arterial hypertension. Patients had their blood pressure measured on admission by a qualified physician prior to the surgery procedure. Diagnosis of arterial hypertension was made when office blood pressure were equal or exceeded the values of 140 for systolic blood pressure (SBP) and/or 90 for diastolic blood pressure (DBP). The number of required measurements, measure techniques and settings were in accordance with the current guidelines for arterial hypertension diagnosis and management of the ESC and European Society of Hypertension. The diagnosis was also made were there were eligible medical records available on previous diagnosis of arterial hypertension or taking prescription hypotensive agents.

Statistical analysis was performed using the SAS software version 8.02 (SAS Institute, Inc., Cary, NC, USA). Continuous data are presented as mean \pm standard deviation (SD) and were compared using the Mann-Whitney test or Student's t-test. Categorical variables were compared using either the $c 2$ or Fisher's exact tests. A p value of less than 0.05 was considered statistically significant, whereas the confidence intervals (CI) were $95 \%$.

\section{Results}

After applying the inclusion and exclusion criteria, the study covered 220 patients, in whom the total hip replacement procedure was performed. The mean age of the study population was $62.2 \pm$ 13.9 years and $42.7 \%$ of patients were male. The body mass index (BMI) in the study population was $27.0 \pm 4.2 \mathrm{~kg} / \mathrm{m}^{2}$. Detailed characteristics of the study population are listed in the Table I. Cardio- 
Table I. Baseline characteristics of the study population

\begin{tabular}{|l|l|}
\hline Parameter & $\begin{array}{l}\text { Value } \\
\mathbf{n}=220\end{array}$ \\
\hline Age (years) & $62.2 \pm 13.9$ \\
\hline Male sex & $94(42.7 \%)$ \\
\hline BMI $\left[\mathrm{kg} / \mathrm{m}^{2}\right]$ & $27.0 \pm 4.2$ \\
\hline SBP $[\mathrm{mm} \mathrm{Hg}]$ & $134.5 \pm 20.4$ \\
\hline DBP $[\mathrm{mm} \mathrm{Hg}]$ & $78.6 \pm 13.1$ \\
\hline HR (beats per minute) & $71.3 \pm 14.0$ \\
\hline Heart failure & $10(4.8 \%)$ \\
\hline Diabetes mellitus & $20(9.1 \%)$ \\
\hline Previously diagnosed arterial hypertension & $128(58.2 \%)$ \\
\hline History of myocardial infarction & $12(5.5 \%)$ \\
\hline History of stroke or TIA & $2(0.9 \%)$ \\
\hline Peripheral artery disease & $2(0.9 \%)$ \\
\hline Diagnosed dyslipidemia & $8(3.6 \%)$ \\
\hline Stable coronary artery disease & $22(10.0 \%)$ \\
\hline $\begin{array}{l}\text { Blood pressure values }>140 / 90 \mathrm{~mm} \text { Hg on } \\
\text { admission }\end{array}$ & $95(43.2 \%)$ \\
\hline
\end{tabular}

Parameters are presented as mean \pm standard deviation or $n(\%)$

$\mathrm{BMI}$ — body mass index; SBP — systolic blood pressure; DBP — diastolic blood pressure; HR — heart rate; TIA — transient ischemic attack

vascular diseases and cardiovascular risk factors were not very frequent among the study population. Of the population, $58.2 \%$ of patients were diagnosed with arterial hypertension previously, $10 \%$ had diagnosed stable coronary artery disease, $5.5 \%$ and $0.9 \%$ underwent myocardial infarction and stroke previously.

After taking blood pressure on admission, it was shown that mean systolic blood pressure (SBP) and diastolic blood pressure (DBP) values were $134.5 \pm$ 20.4 and $78.6 \pm 13.1 \mathrm{~mm} \mathrm{Hg}$, respectively (Figure 1). In $43.2 \%$ of patients the on admission blood pressure values exceeded the threshold of $\geq 140$ and/or $90 \mathrm{~mm} \mathrm{Hg}$. Arterial hypertension was diagnosed de novo in $33(15.0 \%)$ patients.

After dividing patients according to the presence of previously diagnosed arterial hypertension, it was found that patients with the disease were older $(67.5$ \pm 12.3 vs. $54.4 \pm 13.9$ years; $p<0.0001)$, and had higher BMI $\left(27.6 \pm 4.3\right.$ vs. $26.2 \pm 3.8 \mathrm{~kg} / \mathrm{m}^{2} ; \mathrm{p}=$ $0.05)$ than patients without the diagnosed disease. Also, the prevalence of various comorbidities was significantly different between patients with and without previously diagnosed arterial hypertension. Diabetes mellitus was more often found in hypertensive patients $(13.3 \%$ vs. $3.3 \% ; p=0.02)$, they also more often had history of myocardial infarction $(\mathrm{p}=$ $0.02)$ and stable coronary artery disease $(\mathrm{p}=0.001)$ compared to patients without the diagnosis.

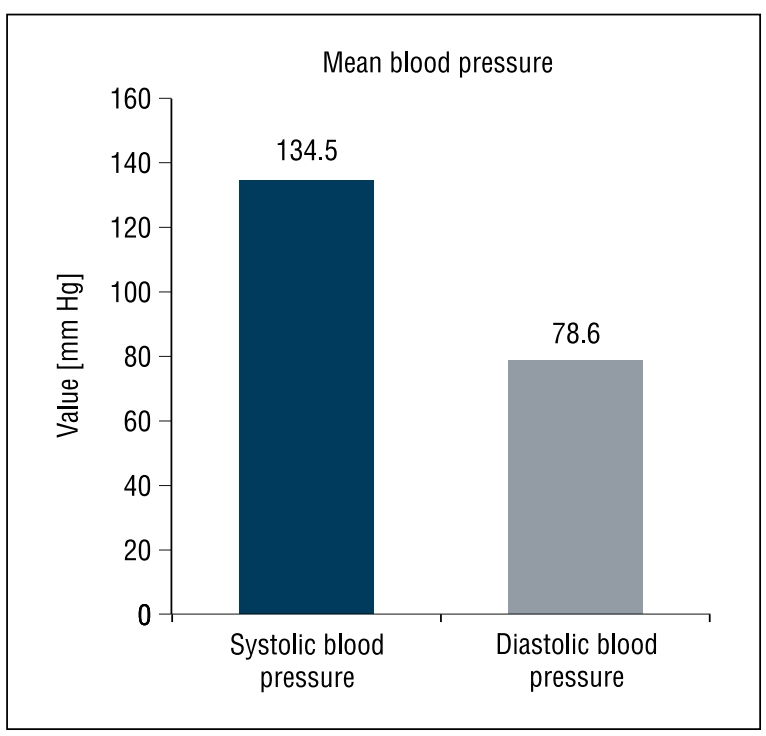

Figure 1. Mean blood pressure on admission

Interestingly, the SBP and DBP values were not significantly higher in patients with previously diagnosed arterial hypertension $(p>0.05)$ than in those without the disease, but blood pressure values $>$ $140 / 90 \mathrm{~mm} \mathrm{Hg}$ on admission were on the edge of statistical significance for being more prevalent in hypertensive patients $(48.4 \%$ vs. $35.9 \% ; \mathrm{p}=0.07)$. Detailed information on the group characteristics are presented in Table II.

\section{Discussion}

Total hip replacement is one of the orthopedic interventions associated with high thromboembolic risk and mortality rate. Perioperative cardiac events are a leading cause of death after non-cardiac surgery [7-9].

Singh et al. have described a population-based cohort of Olmsted County residents who underwent total hip arthroplasty between 1994 and 2008. Ninety-day mortality in this group was $0.7 \%$, thromboembolic events, including deep vein thrombosis and pulmonary embolism have been estimated on $4 \%$ and $6.9 \%$ of population has manifested cardiac events (myocardial infarction, arrhythmia, congestive heart failure) [10].

In spite the fact that patients treated with total hip replacement have a lower comorbidity score than the whole arthritis population, they are at high risk for fatal complications [7]. Numerous high mortality risk factors have been described and divided into modifiable and non-modifiable. The most important are associated with early 90-day mortality and include: fatal myocardial infarction, pulmonary 
Table II. Patient characteristics according to the presence of previously diagnosed hypertension

\begin{tabular}{|c|c|c|c|}
\hline Parameter & $\begin{array}{l}\text { Non-hypertensive patients } \\
\text { ( } \mathrm{n}=92 \text { ) }\end{array}$ & $\begin{array}{l}\text { Patients with previously } \\
\text { diagnosed hypertension } \\
\text { ( } \mathrm{n}=128 \text { ) }\end{array}$ & $\mathrm{p}$ value \\
\hline Age (years) & $54.4 \pm 13.9$ & $67.5 \pm 12.3$ & $<0.0001$ \\
\hline Male sex & $45(48.9 \%)$ & $49(38.3 \%)$ & 0.13 \\
\hline $\mathrm{BMI}\left[\mathrm{kg} / \mathrm{m}^{2}\right]$ & $26.2 \pm 3.8$ & $27.6 \pm 4.3$ & 0.05 \\
\hline SBP [mm Hg] & $130.6 \pm 16.7$ & $137.2 \pm 16.7$ & 0.07 \\
\hline $\mathrm{DBP}[\mathrm{mm} \mathrm{Hg}]$ & $77.7 \pm 10.9$ & $79.2 \pm 14.5$ & 0.50 \\
\hline HR (beats per minute) & $71.1 \pm 13.7$ & $71.5 \pm 14.2$ & 0.58 \\
\hline Heart failure & $0(0.0 \%)$ & $10(8.3 \%)$ & 0.006 \\
\hline Diabetes mellitus & $3(3.3 \%)$ & $17(13.3 \%)$ & 0.02 \\
\hline History of myocardial infarction & $1(1.1 \%)$ & $11(8.6 \%)$ & 0.02 \\
\hline History of stroke or TIA & $0(0.0 \%)$ & $2(1.6 \%)$ & 0.51 \\
\hline Peripheral artery disease & $1(1.1 \%)$ & $1(0.8 \%)$ & 1.00 \\
\hline Diagnosed dyslipidemia & $1(1.1 \%)$ & $7(5.5 \%)$ & 0.14 \\
\hline Stable coronary artery disease & $2(2.2 \%)$ & $20(15.6 \%)$ & 0.001 \\
\hline Blood pressure values $>140 / 90 \mathrm{~mm} \mathrm{Hg}$ on admission & $33(35.9 \%)$ & $62(48.4 \%)$ & 0.07 \\
\hline
\end{tabular}

Parameters are presented as mean \pm standard deviation or $n(\%)$.

$\mathrm{BMI}$ — body mass index; $\mathrm{SBP}$ — systolic blood pressure; $\mathrm{DBP}$ — diastolic blood pressure; $\mathrm{HR}$ - heart rate; $\mathrm{TIA}$ — transient ischemic attack; $\mathrm{AF}$ - trial fibrillation

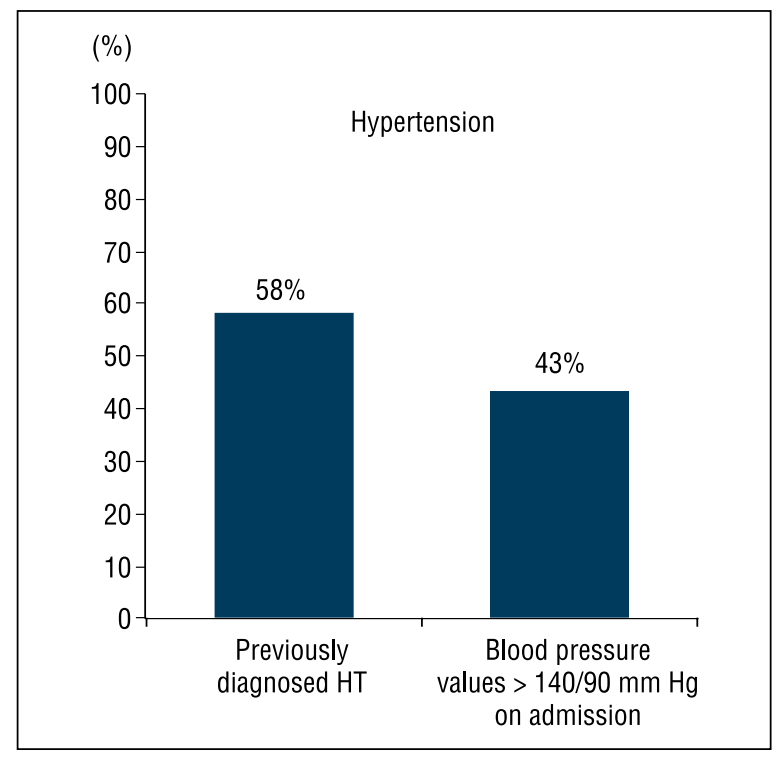

Figure 2. Prevalence of previously diagnosed arterial hypertension versus patients with blood pressure values meeting the criteria for hypertension diagnosis

$\mathrm{BP}$ — blood pressure, HT — arterial hypertension

embolism, postoperative hyperglycemia or elevated perioperative creatinine concentration $[7,8]$. It is also confirmed that the elderly patients especially with history of dementia, preoperative anemia and prolonged hospital stay are more likely to die in the early postoperative period [8]. However, total risk of serious complications after arthroplasty is not significantly high. Available literature reveals that thromboembolic complications such as venous thromboembolism and pulmonary embolism are classified as one of the most frequent, especially among elderly patients $[6,11]$.

For all these reasons it is important to estimate total cardiovascular and thromboembolic risk before surgery in order to reduce mortality in patients undergoing hip replacement.

The thromboembolic risk stratification, especially important in prothrombotic states such as hip replacement, is currently facilitated with few popular risk assessment schemes. The most widely used, most of all in atrial fibrillation patients, but also acute coronary syndromes, pulmonary embolism or prediction of erectile dysfunction is the $\mathrm{CHA}_{2} \mathrm{DS}_{2}$ -VASc score [12-14]. In the $\mathrm{CHA}_{2} \mathrm{DS}_{2}$-VASc score, as well as in other prediction schemes, the arterial hypertension is recognized as a thromboembolic risk factor [15]. Previous research suggests that hypertension is the most prevalent stroke risk factor $(67.3 \%)$, followed by corona ry artery disease (38.4\%). The systematic review emphasizes the importance of arterial hypertension, prior stroke/TIA, advancing age and diabetes as a stroke risk factors. On the other hand, vascular diseases, including myocardial infarction, peripheral artery disease, and complex aortic plaque increase $\mathrm{TE}$ risk in $\mathrm{AF}$ [15].

Therefore, in patients undergoing hip replacement early diagnosis of arterial hypertension can help facilitate the decision on proper management 
and suitable thromboembolic prophylaxis introduction. Assessment of the blood pressure values is important also for the preoperative and postoperative management outside of the coagulation control. It was observed that patient with untreated hypertension had greater decrease in blood pressure and were more exposed to myocardial infarction [16].

Hypertension undoubtedly correlates with higher perioperative risk leading to severe and minor complications including: cardiovascular death, myocardial infarction, heart failure, cerebrovascular accidents and perioperative tachycardia or bradycardia [16]. Moreover, labile blood pressure values may be strongly associated with types of anesthetic drugs used in surgery procedure $[16,17]$. Hypertensive patients seem to have higher cardiovascular lability during anesthesia due to increased systemic vascular resistance $[16,18]$. They are also more sensitive to intubation and laryngoscopy during operation [16, 19]. All these factors have an effect on operation progress and perioperative complications risk. All hypertensive patients should be treated appropriate prior to elective surgical procedure in order to avoid unwanted events during and after surgery [16].

A new predictive model was recently developed to assess the risk of intra-operative/post-operative myocardial infarction or cardiac arrest, using the American College of Surgeons National Surgical Quality Improvement Program (NSQIP) database. The model incorporates risk factors, such as type of surgery, functional status, elevated creatinine ( $>130 \mathrm{mmol} / \mathrm{L}$ or $>1.5 \mathrm{mg} / \mathrm{dL}$ ), American Society of Anesthesiologists (ASA) class, age and is an easily applicable clinically based scheme [9,20].

Also, current 2014 European Society of Cardiology guidelines on cardiovascular assessment and management during non-cardiac surgery mention the significance of cardiovascular risk estimation prior to the procedure [20]. According to guidelines, clinical risk indices are recommended to be used for peri-operative risk stratification. Effective strategies aimed at reducing the risk of perioperative cardiac complications should be considered for two reasons. Firstly, low-cardiac risk patients can be operated without further delay. Secondly, risk reduction by pharmacological treatment is most effective in patients with a suspected increased cardiac risk. Several risk indices have been developed during last 30 years [20].

\section{Conclusions}

Majority of patients scheduled for elective hip replacement surgery is diagnosed with arterial hyperten- sion. Most of the patients have good blood pressure control, but in some cases, the disease is diagnosed de novo. Screening for arterial hypertension is important in this group of patients and can potentially reduce the complication rates of the hip replacement surgery.

\section{References}

1. Platek A.E., Szymanski F.M., Filipiak K.J. et al. Prevalence of arterial hypertension in patients with atrial fibrillation undergoing ablation a prospective, cohort study. Arterial Hypertens. 2015; 19: 135-139.

2. Zdrojewski T., Bandosz P., Rutkowski M. et al. Rozpowszechnienie, wykrywanie i skuteczność leczenia nadciśnienia tętniczego w Polsce — wyniki badania NATPOL 2011. Nadciśnienie Tętnicze 2014; 18: 116-117.

3. Rapsomaniki E., Timmis A., George J. et al. Blood pressure and incidence of twelve cardiovascular diseases: lifetime risks, healthy life-years lost and age-specific associations in $\mathbf{1} \cdot 25$ million people. Lancet 2014; 383: 1899-1911.

4. Kawecka-Jaszcz K., Pośnik-Urbańska A., Jankowski P. Prevalence of arterial hypertension in Poland - impact of gender. Nadciśnienie Tętnicze 2007; 11: 377-383.

5. Kimura Y., Tomiyama H., Nishikawa E. et al. Characteristics of cardiovascular morphology and function in the high-normal subset of hypertension defined by JNC-VI recommendations. Hypertens. Res. 1999; 22: 291-295.

6. Mantilla C.B., Horlocker T.T., Schroeder D.R. et al. Frequency of Myocardial Infarction, Pulmonary Embolism, Deep Venous Thrombosis, and Death following Primary Hip or Knee Arthroplasty. Anesthesiology 2002; 96: 1140-1146.

7. Berstock J.R., Beswick A.D., Lenguerrand E. et al. Mortality after total hip replacement surgery. Bone Joint Res. 2014; 3: 175-182.

8. Aynardi M., Jacovides C.L., Huang R. et al. Risk factors for early mortality following modern total hip arthroplasty. J. Arthroplasty 2013; 28: $517-520$

9. Gupta P.K., Gupta H., Sundaram A. et al. Development and validation of a risk calculator for prediction of cardiac risk after surgery. Circulation 2011; 124: 381-387.

10. Singh J.A., Jensen M.R., Harmsen W.S. et al. Cardiac and thromboembolic complications and mortality in patients undergoing total hip and total knee arthroplasty. Ann. Rheum. Dis. 2011; 70: 2082-2088.

11. Memtsoudis S.G., Pumberger M., Ma Y. et al. Epidemiology and risk factors for perioperative mortality after total hip and knee arthroplasty. J. Orthop. Res. 2012; 30: 1811-1821.

12. Cetin M., Cakici M., Zencir C. et al. Prediction of coronary artery disease severity using CHADS2 and CHA2DS2-VASc scores and a newly defined CHA2DS2-VASc-HS score. Am. J. Cardiol. 2014; 113: 950-956.

13. Saliba W., Rennert G. CHA2DS2-VASc score is directly associated with the risk of pulmonary embolism in patients with atrial fibrillation. Am. J. Med. 2014; 127: 45-52.

14. Szymański F.M., Filipiak K.J., Płatek A.E. et al. Can thromboembolic risk be associated with erectile dysfunction in atrial fibrillation patients? Cardiol. J. 2015; 22: 446-452.

15. Lip G.Y., Nieuwlaat R., Pisters R. et al. Refining clinical risk stratification for predicting stroke and thromboembolism in atrial fibrillation using a novel risk factor-based approach: the euro heart survey on atrial fibrillation. Chest 2010; 137: 263-272.

16. Howell S.J., Sear J.W., Foex P. Hypertension, hypertensive heart disease and peri-operative cardiac risk. Br. J. Anaesth. 2004; 92: 570-583.

17. Goldman L., Caldera D.L. Risks of general anesthesia and elective hypertension and perioperative risk operation in the hypertensive patient. Anesthesiology 1979; 50: 285-292.

18. Kaplan N.M.. Clinical Hypertension, 8th edn. Lippincott Williams and Wilkins, Philadelphia 2002; 35-36, 92-96.

19. Prys-Roberts C., Greene L.T., Meloche R., Foex P. Studies of anaesthesia in relation to hypertension. II. Haemodynamic consequences of induction and endotracheal intubation. Br. J. Anaesth. 1971; 43: 531-547.

20. 2014 ESC/ESA Guidelines on non-cardiac surgery: cardiovascular assessment and management. Eur. Heart J. 2014; 35: 2383-2431. 